
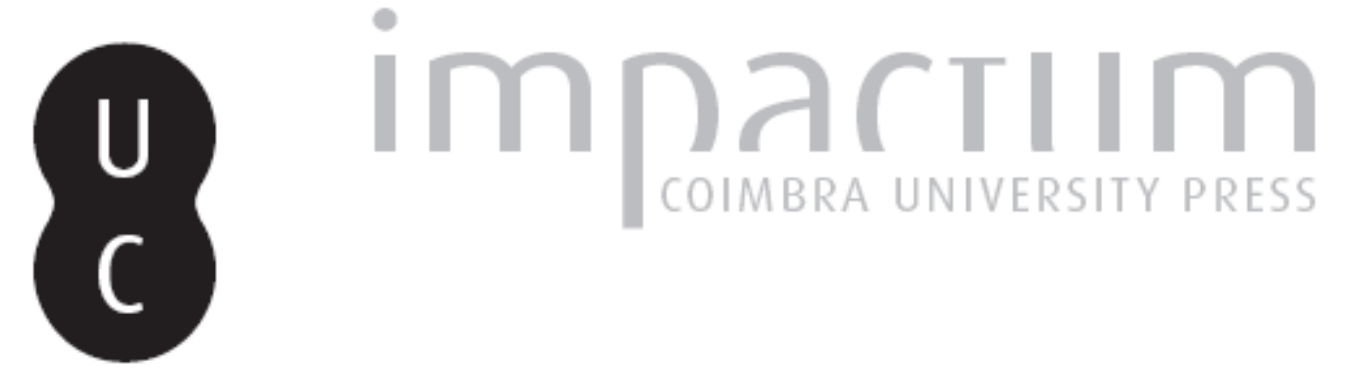

\title{
Filosofia da arquitectura e do espaço: aproximações histórico-conceptuais ao modernismo
}

\author{
Autor(es): $\quad$ Ferrer, Diogo
}

Publicado por: Imprensa da Universidade de Coimbra

URL

persistente:

URI:http://hdl.handle.net/10316.2/42838

DOI:

DOI:http://dx.doi.org/10.14195/0872-0851_49_1

Accessed : $\quad$ 26-Apr-2023 12:19:21

A navegação consulta e descarregamento dos títulos inseridos nas Bibliotecas Digitais UC Digitalis, UC Pombalina e UC Impactum, pressupõem a aceitação plena e sem reservas dos Termos e Condições de Uso destas Bibliotecas Digitais, disponíveis em https://digitalis.uc.pt/pt-pt/termos.

Conforme exposto nos referidos Termos e Condições de Uso, o descarregamento de títulos de acesso restrito requer uma licença válida de autorização devendo o utilizador aceder ao(s) documento(s) a partir de um endereço de IP da instituição detentora da supramencionada licença.

Ao utilizador é apenas permitido o descarregamento para uso pessoal, pelo que o emprego do(s) título(s) descarregado(s) para outro fim, designadamente comercial, carece de autorização do respetivo autor ou editor da obra.

Na medida em que todas as obras da UC Digitalis se encontram protegidas pelo Código do Direito de Autor e Direitos Conexos e demais legislação aplicável, toda a cópia, parcial ou total, deste documento, nos casos em que é legalmente admitida, deverá conter ou fazer-se acompanhar por este aviso.

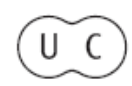




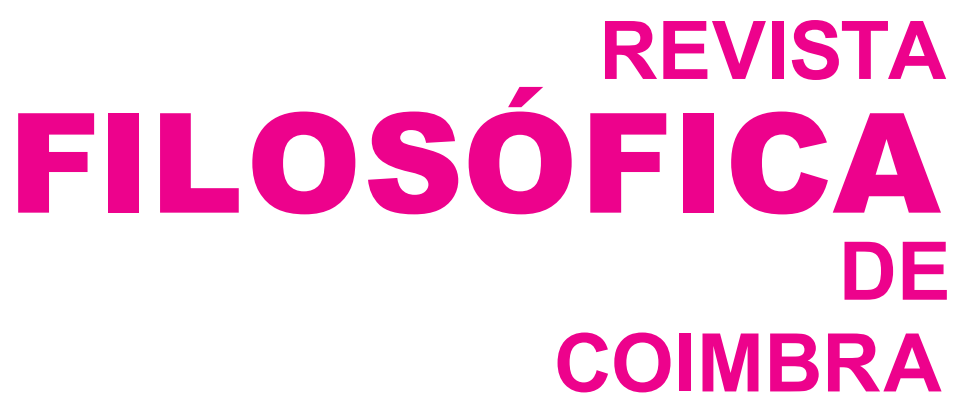

vol. 25 - número 49 - março 2016

vol. 25 - número 49 - março 2016

Fundação Eng. António de Almeida

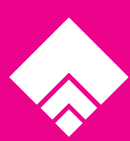




\title{
FILOSOFIA DA ARQUITECTURA E DO ESPAÇO: APROXIMAÇÕES HISTÓRICO-CONCEPTUAIS AO MODERNISMO
}

\author{
PHILOSOPHY OF ARCHITECTURE AND OF SPACE: HISTORICAL \\ AND CONCEPTUAL APPROACHES TO MODERNISM
}

DIOGO FERRER*

Resumo: Este artigo visa mostrar a inserção da arquitectura moderna no contexto da reflexão filosófica, a partir de Hegel até Heidegger e outros críticos mais recentes da concepção moderna da arquitectura e do espaço. Começando pela defesa da tese de que é a Estética de Hegel que inaugura, na história da arte, a possibilidade do estudo contemporâneo, semântico e conceptual, das formas arquitectónicas e do seu desenvolvimento histórico, é também discutida a tese hegeliana do fim da história da arquitectura, com recurso em especial a posições de A. Danto (1-3). O conteúdo ideológico da revolução modernista, com referência especialmente a Le Corbusier, é confrontado com aspectos centrais da filosofia que lhe é contemporânea, como sejam o logicismo ou o funcionalismo, segundo autores como Wittgenstein ou Husserl, com os seus antecedentes filosóficos modernos e com alguns dos seus críticos e reacções filosóficas (4-6). Neste âmbito, é destacado o estudo da ponte pelo Heidegger tardio, como exemplo de obra arquitectónica, concluindo-se com a defesa do carácter eminentemente reflexivo da arquitectura moderna (7-8).

Palavras-Chave: Filosofia da Arquitectura; Estética; Hegel; Heidegger; Le Corbusier; Arquitectura Moderna; Crítica ao Modernismo

\begin{abstract}
This paper aims to show how modern architecture is inserted in the context of the philosophical thought, from Hegel to Heidegger and other more recent critiques of the modernist conception of architecture and
\end{abstract}

Zusammenfassung:ZieldiesesAufsatzes ist, die moderne Architektur im Kontext der philosophischen Reflexion zu erörtern, mit Schwerpunkt auf Hegel, Heidegger und anderen Kritikern des modernen Begriffs der Architektur und

* Professor Associado da Universidade de Coimbra; ferrer.diogo@gmail.com 
space. Beginning with the defense of the point that it was Hegel's Aesthetics that opened the way for a contemporary - semantical and conceptual - study of architectural forms and its historical developement, the paper discusses the Hegelian thesis about the end of the history of architecture, with special reference to A. Danto's position (1-3). The ideological content of the modernist revolution, mainly as stated by Le Corbusier, is confronted with some central concepts of contemporary philosophy, as logicism or functionalism, according to writers as Wittgenstein and Husserl (4), with some modern antecedents (5) and with philosophical reactions (6). The late Heidegger's study of the bridge is focused, as an example of architectural work, and the paper concludes with a defense of the reflective character of modern architecture (7-8).

Key-Words: Philosophy of Architecture; Aesthetics; Hegel; Heidegger; Le Corbusier; Modern Architecture; Critique of Modernism des Raums. Der Aufsatz stellt zunächst die These auf, dass Hegels Ästhetik neue Möglichkeiten für die Kunstgeschichte eröffnet hat. Erst danach wird eine semantische und begriffliche Untersuchung der architektonischen Formen und deren geschichtliche Entwicklung aus heutiger Sicht möglich. In Zusammenhang damit wird Hegels These vom Ende der Geschichte der Architektur diskutiert, insbesondere in Anlehnung an A. Dantos Stellungnahme (1-3). Der ideologische Gehalt der modernistischen Revolution, mit besonderem Hinweis auf Le Corbusier, wird mit einigen Hauptgedanken der derzeitigen Philosophie, wie Wittgensteins und Husserls Logizismus und Funktionalismus, sowie anderer Vorläufer, konfrontiert (4-6). Im Rahmen der Kritik am modernistischen Raum- und Bau-Konzept, wird zuletzt Heideggers Studie der Brücke als Beispiel eines Bauwerks diskutiert, was schlussendlich $\mathrm{zu}$ einer Hervorhebung des wesentlich reflexiven Charakters der modernen Architektur führt (7-8).

Schlüsselwörter: Philosophie der Architektur; Ästhetik; Hegel; Heidegger; Le Corbusier; Moderne Architektur; Modernismus-Kritik

\section{Sobre a definição da $\operatorname{arte}^{1}$}

A reflexão filosófica sobre a arquitectura, especialmente da perspectiva da história da arte, foi tornada possível e inaugurada pelas Lições sobre Estética de Hegel. Nestas Lições, encontra-se uma renovação das definições e do tratamento tradicionais da arte e da estética, feita de tal modo que com elas

1 Este artigo baseia-se numa conferência apresentada no Curso de Doutoramento em Arte Contemporânea do Colégio das Artes da Universidade de Coimbra, em 22 de Novembro de 2013. Agradeço à Doutora Rita Marnoto o convite para essa participação. 
se abrem possibilidades inteiramente novas de compreensão do fenómeno estético.

Hegel começa por retornar a uma concepção totalmente objectiva do valor estético, que tinha sido substituída pela estética da recepção, no Séc. XVIII, com o seu culminar na Crítica do Juízo de Kant. Partindo do problema da relação da liberdade com a natureza, Kant instituiu uma estética segundo a qual o valor reside nas condições de possibilidade do juízo de gosto. Um sujeito capaz tanto de conhecimento de uma natureza objectiva quanto de liberdade é também necessariamente um sujeito de experiencia estética e de juízo de gosto. Contudo, dada a inadequação fundamental entre a experiência objectiva e a liberdade autónoma da razão humana, a experiência estética aparece para esta como um substituto subjectivizado do conhecimento objectivo, substituto onde a liberdade aparece como se pudesse ser fenómeno. No belo e no sublime, aquilo que objectivamente não pode ser exposto - porque não cabe nas condições da experiência objectiva - é apresentado, mas somente para a reflexão do sujeito, como se fosse objectivo. A fruição estética distingue-se da fruição natural, ou do meramente agradável, por ser, pensa Kant, desinteressada, ou seja, caracteriza-se por não ter nenhum fim determinado. E, por ser desinteressado, o juízo de gosto está liberto da limitação individual ou da finalidade determinada característica do agradável e da fruição natural, e reivindica, por conseguite, validade universal - como se se tratasse de um juízo sobre propriedades objectivas, embora não o seja senão para a reflexão do sujeito estético.

Hegel, pelo contrário, entende que a experiência estética e o estatuto da obra de arte nada têm que ver com as condições da recepção do observador e da sua reflexão, nada têm de subjectivo, nem tão-pouco são uma objectividade secundária, como se fosse uma propriedade objectiva de um objecto, sem que efectivamente o seja. Retomando uma definição tradicional, o belo é então em primeiro lugar manifestação objectiva, o brilho de uma plenitude e de um objecto não natural, de uma essência que não se pode experienciar na natureza. Como se lê em Plotino, por exemplo,

"a beleza de uma cor simples vem-lhe de uma configuração que domina a obscuridade da matéria e da presença de uma luz incorpórea que é razão e forma. Daí resulta que, de entre todos os corpos, o fogo é belo em si mesmo [...]. Ele ilumina e brilha porque é uma forma [eidos]." "O belo é o lugar das formas." 2

Hegel recupera este brilho real da forma sob uma compreensão renovada, ao entender a relação entre ser e aparecer dialecticamente. Isto signifi-

2 Plotin, Prémière Ennéade, trad. E. Bréhier, Paris, 1997, 131, 147. 
ca, mais claramente, que "a aparência é essencial à essência" ["Doch der Schein selbst ist dem Wesen wesentlich"]. ${ }^{3}$

$\mathrm{O}$ essencial e a aparência não se distinguem essencialmente. $\mathrm{E}$ a arte é, com certeza, manifestação, mas não manifestação de algo que não pode aparecer em si mesmo, porque simplesmente não é sensível, como no caso de Plotino ou Kant; o belo não é a aparição de um eidos (forma ou ideia) que, como insiste Plotino, afecta e atrai a alma porquanto não pertence ao corpóreo. O que a arte mostra, segundo Hegel, não é nem um objecto corpóreo, nem uma forma-objecto transcendente que não se deixa mostrar senão inadequadamente aos olhos sensíveis, mas é o próprio mostrar.

$\mathrm{O}$ acto de mostrar é o essencial que, na arte, está sob uma forma reflectida em si mesma. Um objecto não artístico mostra-se, mas não fala do seu próprio aparecer, ou só fala deste por intermédio da possível reflexão do seu observador. $\mathrm{O}$ objecto artístico, pelo contrário, fala objectivamente do aparecer porque, aparte e além da sua condição também natural, não é senão isso: aparecer. Se perante um objecto não artístico podemos estar distraídos, e normalmente estamos, da sua aparição, que só pela reflexão podemos tematizar, a obra de arte não pode ser percepcionada sem a atenção ao acto de mostrar, dado que ela não é senão isso. A arte é então ideia (Idee), porque é directamente o mostrar-se a si, não por interposto observador, mas directamente, como a presença imediata e efectiva do mostrar-se, ao contrário do belo kantiano, cujo lugar de ocorrênca é o sujeito individual observador, ou do belo plotiniano, que remete para um outro lugar fora do sensível, onde se encontram as ideias (eidos ou forma).

Em termos técnicos, a arte pertence, na posição hegeliana, ao denominado "espírito absoluto", visto que é manifestação auto-referente, e o que existe na arte (a manifestação, brilho) corresponde ou é directamente o seu conceito (o manifestar-se). Nela, conceito ou pensamento, por um lado, e realidade, por outro, não se distinguem e, consequentemente, o seu conceito não deve ser procurado fora dela. Por estas razões, porque se dá a si mesmo o seu sentido e realidade, a arte é também - não menos importante - objecto que mostra principalmente autonomia. Estas características, de ser manifestação, auto-manifestação, pensamento directamente existente, e autónomo, definem o que Hegel denomina Geist, 'espírito', e a arte é, por isso, realidade do espírito, o qual não é, aliás, senão como realmente existente. Explica-se assim que a experiência estética só secundariamente consiste em sensações, impressões ou livre jogo subjectivo.

A arte, segundo Hegel, é pensamento, ou seja, inteiramente conceptual.

3 Hegel, Vorlesungen über die Ästhetik II, in Werke 14, Frankfurt a.M., 1995, 13,21 . 
"A necessidade geral e absoluta de que a arte [...] nasce encontra a sua origem em que o homem é consciência pensante, i.e., que o homem torna para si o que ele é e, em geral, tudo aquilo que é. As coisas da natureza são somente imediatamente e uma vez, mas o homem, como espírito, duplica-se, na medida em que, em primeiro lugar, como natureza, ele é, e então, do mesmo modo, é para si, intui-se, representa-se, pensa, e só por intermédio deste ser-para-si activo é espírito."4

A arte é então a manifestação do próprio conteúdo do espírito, da sua liberdade, do seu carácter manifestativo e auto-manifestativo. Trata-se, então, na arte, antes de mais de se objectivar e de se mostrar e ver a si mesmo.

Ao entender, assim, a arte como manifestação essencial do pensamento ou do espírito a si mesmo, Hegel recupera, por um lado, a objectividade da arte e da experiência estética. Mas, por outro lado, ao fazer da manifestação o momento essencial da ideia estética, a arte passa a integrar a própria constituição do espírito que é para si, e é anulada a diferença entre o ideal e o real. O conceito, ou a ideia, não está separada, não é degradada nem perde a sua essência na sua manifestação material; pelo contrário, é nessa manifestação que se constitui e vem a ser.

\section{A arquitectura hegeliana}

A nova perspectiva aberta pela Estética de Hegel tem duas consequências, que permitem pensar a arte e a estética de um modo inusitado até então. Por um lado, conduz à consideração da arte como parte integrante do processo histórico, cultural e social em que o espírito se realiza objectivamente a si. Não se entende a arte segundo o modelo de um observador isolado que contempla um objecto, e que o pode ajuizar como belo ou feio segundo as suas faculdades subjectivas, sensíveis e racionais. A arte recebe existência objectiva no mundo espiritual, que é também individual e antropológico, mas sobretudo histórico e colectivo, e o juízo de gosto, singular ou psicológico, torna-se largamente irrelevante, substituído por uma "ciência" objectiva, que integra histórica e socialmente a obra de arte. A manifestação objectiva do espírito não depende do gosto individual ou privado, mas é um fenómeno social e ético - no sentido da vida colectiva das sociedades - que obedece a uma lógica histórica de desenvolvimento. Tudo, na arte e na sua linguagem, ganha um sentido contextual e conceptual, e é descoberta assim, pela primeira vez, uma sistemática "conexão entre o significado e a configuração" da obra. ${ }^{5}$

${ }^{4}$ Hegel, Werke 13, 51.

5 "Connection between meaning and configuration" (R. D. Winfield, "The Challenge of Architecture to Hegel's Aesthetics" in W. Maker (ed.), Hegel and Aesthetics, Albany, 2000, 97-111, 99. 
Em consequência, por outro lado, a arte passa a ser entendida como "inteiramente aberta ao conceito", i.e., é pensamento e, como tal, o seu significado particular pode ser estudado conceptualmente. A obra passa a ter um significado conceptual patente em toda a sua forma específica, nos seus materiais, época histórica, estilo ou ornamentação. Só poderíamos subscrever o comentário de Richard Dien Winfield de que

"o contraste entre o tratamento da arquitectura de Hegel e dos celebrados Dez Livros da Arquitectura de Vitrúvio é indicativo da distância que separa Hegel da concorrência. Vitrúvio ignora totalmente a conexão entre o significado e a configuração na arquitectura, oferecendo somente noções vagas de harmonia e proporção, que oferecem pouca inteligência da significação e beleza distintivas do templo grego, no qual foca a sua atenção." 6

Todos os pormenores estilísticos, na consideração hegeliana, ganham o sentido do pensamento e do conceito.

A análise hegeliana da arquitectura é exemplar desta consideração conceptual e auto-conceptual. A arquitectura "é o começo da arte", cuja

"primeira tarefa consiste em configurar o que é objectivo em si mesmo, i.e., o solo da natureza, o ambiente externo do espírito, e imprimir, assim, significado e forma no que não tem interior [...]. A arte a que esta tarefa foi proposta é a arquitectura."7

No seu começo arquitectónico, a arte é o espírito plenamente exterior a si, que se vai indicar somente, sem estar presente ou minimamente reconhecido e expresso como tal. Dada essa exterioridade, dois aspectos se encontram na arquitectura como arte primordial: por um lado, ela deve preceder a distinção entre meios e fins; por outro, deve exprimir os aspectos primordiais da exterioridade.

A arquitectura antecede a distinção meio e fim, como nos exemplos estudados por Hegel da arquitectura pré-clássica, que denomina simbólica, da "construção da torre babilónica", onde "a comunidade da construção é simultaneamente o fim e o conteúdo da própria obra," $"$ bem como em construções de obeliscos ou estatuária colossal, onde a finalidade do abrigo ou habitação não está ainda destacada da simples apresentação simbólica do construir e do elo político. A construção é o laço e a ordenação política de um espírito ainda exterior a si-e, de modo esclarecedor, o filósofo considera que a arquitectura simbólica, no momento histórico em que se exprime adequadamente, tem

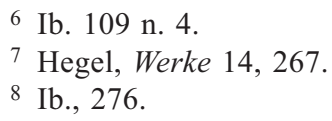

8 Ib., 276. 
a mesma função que, "para nós, têm os costumes, os hábitos e a ordenação constitucional do estado." 9

A separação entre meio e fim é típica do espírito que começa a tematizar e racionalizar o seu despertar, o seu habitar, bem como a sua individualidade própria. Isto manifesta-se, em primeiro lugar, através da arquitectura funerária, cujo exemplo mais representivo na época simbólica é a pirâmide. A reflexão sobre, e além da morte como mero acontecimento natural vai fazer figurar a individualidade do espírito no túmulo. A arquitectura, como arte funerária, assume então pela primeira vez a sua finalidade de ser um espaço que encerra, e que determina o espaço, dividindo-o em exterior e interior. A arquitectura vai tratar doravante da habitação. Na habitação funerária, contudo, os traços simbólicos - i.e., não teleológicos ou técnicos - permanecem, e ela não integra nem expõe organicamente o espírito que a habita. Os traços simbólicos exibem-se ainda no carácter não conforme aos fins de habitação da construção. Daí a sua forma triangular, que é não técnica e anti-funcional. A sua forma é, pois, uma forma abstracta - porque sem função -, onde "o ângulo recto ainda não predomina como na casa propriamente dita." 10 Como figuração ainda incoativa e transicional do espírito, esta é uma habitação de um morto, que se fecha em si mesma, da base ao topo, expondo a finalidade de invólucro habitável, mas ao mesmo tempo excluindo tal finalidade e reafirmando a sua característica não mais que simbólica e exterior.

A transição para a arquitectura clássica é feita pela coluna, que reúne o princípio orgânico e vegetal da natureza com o entendimento, pela sua função e ordenação regulada e bem finalizada. A relação meio e fim torna-se adequada pelo privilégio do ângulo recto, que permite delimitar um espaço efectivamente habitável, habitação destinada agora à estátua de um deus. A arquitectura clássica, segundo Hegel, não exprime o espírito, como é o caso na arquitectura simbólica, mas está ao serviço dele. No templo clássico,

"nada aspira à elevação, [e] a largura, como fundação sobre a terra, firme e confortável, permanece o principal; a altura é tomada sobretudo da estatura humana, e só se expande em conformidade com a expansão da largura e da profundidade do edifício." 11

A mesma horizontalidade é marcada pelo ângulo recto, o capitel e a arquitrave, entre outros pormenores.

Segundo os termos da definição hegeliana, "a arquitectura é a arte no exterior." 12 A exterioridade significa, em geral, a exterioridade do conceito.

\footnotetext{
9 Ib., 296-297.

$10 \mathrm{Ib}$.

$11 \mathrm{Ib}, 319$.

12 Ib., 271.
} 
Deve ser entendida como a negação da ligação conceptual entre as coisas, dita "interior". Assim, a exterioridade designa a sua posição numa comunidade e relação que é sensível e não directamente conceptual e lógica, e a arquitectura é a reposição da ligação conceptual, mas a partir da sua exterioridade mais pura, apesar de poder conter também outros elementos de conteúdo artístico. Esta pura exterioridade do conceito recebe o nome de espaço, e a arquitectura é, por isso, antes de mais arte do espaço, compreendendo as configurações espaciais e materiais primitivas. Segundo Hegel, o espaço só concretiza a sua diferença na medida em que é matéria, e esta contém - por razões que não poderíamos expor com mais detença - a determinação essencial do peso. Deste modo, a arquitectura lida essencialmente com a materialidade e o peso. E estes são os factores essenciais no seu desenvolvimento.

O templo clássico representa o peso, e a sua superação, pelo encurvamento da coluna na ordem dórica e pelo seu adelgamento na jónica e na coríntia. No entanto, o fim da arquitectura clássica passa, segundo Hegel, pelo arco, que exibe a superação do peso e da matéria ao pôr o centro de gravidade fora da matéria. Mas é somente no arco em ogiva, próprio da arquitectura romântica, que Hegel vê realizada na catedral gótica, que a materialidade aponta verticalmente para além de si. A gravidade desaparece inteiramente em agulhas e arcos quebrados e sem a marcação de um termo horizontal por capiteis e arquitraves, entre diversos outros elementos da linguagem romântica. Esta acentua também, ao contrário do peristilo clássico, a separação entre exterior e interior, fazendo da interioridade, de que toda a comunidade participa, o aspecto central do espírito. Ao contrário do carácter diurno e natural da luz do templo clássico, a modução da luz pelo vitral na construção gótica mostra também que "aqui um outro dia deve iluminar, não o dia da natureza exterior." 13

\section{O fim da arquitectura e mais além}

E por fim, dada a exterioridade, materialidade e gravidade que lhe são próprias, o recurso último da arquitectura na sua auto-superação é o de "não admitir o material, o maciço, na sua materialidade, em toda a parte o interromper e despedaçar, retirar-lhe a ilusão da sua consistência imediata e da sua autonomia." 14 Segundo Hegel, este é o limite último da arquitectura mas, também, o final da sua história e das suas possibilidades de desenvolvimento. Para o autor, que inaugurou o tratamento semântico e filosófico sistemático da arquitectura, esta termina as suas possibilidades com a arqui-

\footnotetext{
13 Ib., 338.

14 Ib., 345.
} 
tectura romântica, ou gótica. Deverá dizer-se então que tudo o que sucedeu à arquitectura desde o final da Idade Média até ao início do século XIX é, segundo o nosso autor, como que uma pós-arquitectura que somente repetiu as linguagens anteriores, ou cujo significado não mais pode trazer algo de radicalmente novo. Ou esta conclusão significa também que a catedral gótica encarna aquilo que de mais elevado a arquitectura pôde exprimir, não só nas suas possibilidades plásticas, como também no seu significado para a vida de uma comunidade.

Assim como podemos observar o termo da arquitectura como a superação, nas suas formas e através delas, do próprio conceito da arquitectura, todo e qualquer desenvolvimento encontra, segundo Hegel, um termo, um esgotamento das suas possibilidades. E, assim, é a própria arte em geral que encontra também um fim para o seu desenvolvimento. Perante esta posição, justifica-se uma longa citação de uma passagem bem conhecida, principalmente por meio de Arthur Danto, da Estética de Hegel. A arte

"é e permanece para nós algo de passado. Ela perdeu para nós uma genuína verdade e vivacidade, e, mais do que afirmar a sua necessidade passada, ou assumir o seu elevado posto, está hoje deslocada para a nossa representação. Aquilo que em nós é hoje estimulado pela obra de arte é, além da fruição imediata, também o nosso juízo, na medida em que submetemos o conteúdo e os meios de exposição da obra de arte, bem como a adequação ou inadequação de ambos, à nossa consideração pensante. A ciência da arte é, por isso, ainda muito mais necessária hoje do que nos tempos em que a arte garantia, por si mesma como arte, já uma completa satisfação. A arte convida-nos à consideração pensante $\mathrm{e}$, na verdade, não com o fito de novamente apelar à arte, mas para conhecer cientificamente o que ela é." 15

A tese subjacente a este conhecido tema do fim da arte é a de que a tomada de consciência pela reflexão, o juízo e o pensamento, que o próprio Hegel inaugurou, como começámos por dizer, transforma o estatuto da arte como objecto e fonte imediata de fruição e de sentido. Aquilo que era presente, no sentido de imediato e justificado pela imediatez da sua fruição e do seu exercício simples, passa a carecer de uma justificação ao nível científico (i.e. conceptual). A arte é passado porque ser passado, neste sentido, significa necessitar de uma justificação conceptual e deixar de valer incondicionalmente como substância fundamental da manifestação do espírito a si mesmo. Poderá recordar-se aqui o famoso dito de Hegel de que "o mocho de Minerva levanta vôo após o crepúsculo," ou seja, a teoria é sempre historicizante no sentido de tratar de objectos que já não estão presentes na sua imediatez

15 Hegel, Werke 13, 25-26. 
originária. A este respeito, podem ler-se as palavras com que Adorno abre a sua Teoria Estética:

"Tornou-se manifesto que tudo o que diz respeito à arte deixou de ser evidente, tanto em si mesma como na sua relação ao todo, e até mesmo ao seu direito à existência. A perda do que poderia fazer de modo não reflectido ou sem problemas não é compensada pela infinidade manifesta do que se tornou possível e que se propõe à reflexão. $\mathrm{O}$ alargamento das possibilidades revela-se em muitas dimensões como um estreitamento. A extensão imensa do que nunca foi pressentido, a que se arrojaram os movimentos artísticos revolucionários cerca de 1910, não proporcionou a felicidade prometida pela aventura." 16

Por isso, como é claro, o denominado "fim da arte", nas duas versões referidas, como o questionamento da sua justificação, bem como o menos referido fim da arquitectura, não significa, de modo nenhum que a arte, ou a arquitectura, não continuem a ser feitas após o eventual esgotamento do seu sentido histórico. O resultado desta pós-história, segundo podemos também depreender do textos citados, é a perda de uma linearidade para o seu desenvolvimento e interpretação, a pluralidade das formas e das expressões, a contaminação com outras expressões do espírito e a questionabilidade do seu estatuto e sentido. Se assim é, de facto a existência de arquitectura depois do Renascimento, com o consequente retorno a formas clássicas, ou de arte em geral depois dos últimos duzentos anos, não significa uma refutação da tese, enunciada por Hegel há dois séculos, de que a arte é algo de "passado". Segundo a interpretação de Danto, o significado da pós-história é que “a extensão do termo 'obra de arte' é hoje inteiramente aberta, de tal modo que vivemos em um tempo em que tudo é possível para os artistas, em que não há mais [...] um 'limite da história' [pale of history]." Por isso, embora o nosso período continue a ser definido e limitado segundo o "modo como nos relacionamos com as formas", no período pós-histórico "todas as formas são nossas". ${ }^{17}$

\section{Sobre o sentido do modernismo}

Segundo Danto, "o fim da arte consiste em tomar consciência da verdadeira natureza filosófica da arte," o que começa por acontecer no "período

16 Th. Adorno, Teoria Estética, trad. A. Morão, Lisboa, 1988, 11.

17 Arhur C. Danto, After the End of Art. Contemporary Art and the Pale of History, New Jersey, 1997, 197-199. 
do modernismo, construído como a época dos manifestos."18 O manifesto é como um programa filosófico para a arte, uma tomada de consciência pretensamente absoluta e definitiva que procura integrar um estilo artístico em definições de como a arte deve ser e de como se deve relacionar com a vida.

$\mathrm{O}$ modernismo arquitectónico está ligado a alguns textos com o carácter de manifesto, onde se poderiam destacar os conhecidíssimos "Ornamento e Crime" de Loos e Por uma Arquitectura, de Le Corbusier. Ou poderia ainda referir-se um outro texto que, não obstante a forma de tratado, é inteiramente contemporâneo do modernismo arquitectónico, no espírito e na expressão, e quase um manifesto programático, a saber, o Tractatus logico-philosophicus de Wittgenstein. O manifesto é pós-histórico no sentido proposto por Danto, de ligar a arte ao pensamento conceptual, e de integrar a arte e a sua compreensão em relações mais vastas do que a fruição imediata ou sentimental. Mas o manifesto não é pós-histórico no sentido de fazer admitir que, como na pós-história, dado que não há barreiras que tornem obrigatório, ou possível, um fio histórico de desenvolvimento, "todas as formas são nossas".

Neste sentido, os manifestos representam o modernismo apenas como limite da história, além do qual se encontraria então o terreno pós-histórico. Enquanto fecho da história, o modernismo procura realizar, por um lado, um retorno a uma origem ou a uma simplicidade elementar da expressão, e a uma conciliação da consciência com a realidade do seu mundo social, político e económico, e, por outro lado, também um ir além da história. Esta conciliação é, segundo Le Corbusier, uma questão de verdade da consciência, numa referência explícita à questão: "a mentira é intolerável. Perecemos na mentira." $19 \mathrm{O}$ retorno a uma origem clássica e intemporal não é senão o retorno a uma conciliação plena da consciência de uma época com a sua verdade, na tese antiga, que já Hegel defendeu, de que o classicismo grego representa a reunião das faculdades estéticas, éticas, religosas, económicas e políticas do cidadão numa unidade feliz.

O paralelo de Le Corbusier dos templos dóricos com os automóveis ${ }^{20}$ mostra que na época da técnica industrial, o espírito encontra a sua verdade em objectos técnicos com uma configuração adequada à função, assim como os templos exprimiam a suposta verdade da consciência religiosa antiga. A verdade é adequação da forma ao conteúdo, da forma artística ao conteúdo esencial e substancial da época. A comparação do Parténon com uma máquina industrialmente produzida em série não se funda, na verdade, numa identidade, semelhança, ou sequer numa analogia, mas numa proporção. A máquina está para nós assim como o templo estava para os gregos. A ver-
18 Ib., 30-31.
19 Le Corbusier, Vers une architecture, Paris, 1995 [1923], 5.
20 Ib., 106-107. 
dade da consciência grega era a adequação entre a ideia e a sua manifestação essencialmente finita e auto-contida (daí as formas da finitude marcadas no templo clássico, como vimos); assim como a verdade da nossa consciência é a técnica. A eliminação do ornamento na obra moderna é a verdade no sentido de identidade entre forma e conteúdo, e ao conteúdo funcional da consciência técnica deve corresponder uma forma artística igualmente funcional.

O modernismo oscilará também numa complementaridade entre, por um lado, a negatividade e abstracção da forma, que torna sem sentido todo o acréscimo ornamental, e, por outro, a funcionalidade pragmática, que reconduz o significado à prática vital. A mesma abstracção lógica, que reconduz a forma à função e elimina o ornamento retórico encontra-se no Tractatus de Wittgenstein, no positivismo lógico ou, de um modo diferente, apesar de procurar manter uma subjectividade como fundamento, também na redução da atitude natural em Husserl; o momento pragmático, por outro lado, segundo o qual o sentido deriva do uso, encontra-se claramente definido tanto no Heidegger de Ser e Tempo como no segundo Wittgenstein. Se em Husserl toda a situação e atitude do sujeito real, originário da natureza e da história, é posta entre parênteses, i.e., reduzida e substituída por um cogito que é a pura forma essencial da mostração, no Tractatus de Wittgenstein a essência da mostração não é alguma forma reflexiva do ego mas a forma proposicional lógica que tem por única função dizer os factos. A estrutura lógica da linguagem é absolutamente explícita, e exclui do domínio do sentido tudo aquilo que não se reduza à função rigorosa de exprimir os factos do mundo. Toda a reflexão, todo o domínio não demonstravelmene factual, é excluído do sentido, ficando a linguagem remetida à sua exclusiva funcionalidade de representação de factos - assim como na arquitectura destes anos não pode haver forma sem função. Juntamente com a retórica e a reflexão sobre si mesma, desaparecem do domínio dizível, reduzido exclusivamente aos factos verificáveis, todas as questões existenciais, éticas, estéticas e religiosas. Na sua filosofia tardia, por seu turno, o sentido é assumido por Wittgenstein como pura acção, ficando excluída qualquer actividade mental do sujeito como fonte de significação. Esta é, por conseguinte, mera acção exterior, sendo toda a referência à interioridade da consciência um uso erróneo da linguagem. Assim, o modernismo procura eliminar a consciência privada e selar toda a reflexão como sem sentido, assumindo a acção como justificação de si própria. Todo o enunciado que não se limite a constituir uma prática social e normativamente aceite deve ser considerado como sem sentido. Embora por vias distintas, o afastamento do solo real do mundo histórico e natural, a anulação da consciência individual ou da reflexão, ou um funcionalismo radical são comuns a toda a filosofia do modernismo. 


\section{Modernismo e modernidade}

O modernismo reproduz mais uma vez, com um novo fôlego, o princípio moderno da fundamentação, princípio na verdade já secular, que consiste em retornar às evidências originárias e às funções elementares da consciência $\mathrm{e}$ da expressão não soterradas pela carga inerte da história. A ligação da fenomenologia de Husserl ao cartesianismo, que se torna explícita nos anos 20, é um outro exemplo decisivo dessa retomada da modernidade na época do modernismo arquitectónico.

A intenção deste retorno é a supressão da consciência histórica, supressão que simultaneamente termina um desenvolvimento - como pretendia Hegel - e inicia um período de progressiva pós-história, segundo os termos já referidos de Danto. A absoluta contemporaneidade, até onde podemos ver, intemporal, de muitas obras deste período e ideologia arquitectónicos (como, por exemplo, a Casa Steiner de Loos, a Casa Schröder de Rietveld, ou outros), mostra o assinalável êxito deste retorno, que marca efectivamente um nec plus ultra. O tempo da expressão parece com efeito impossivelmente congelado nestas obras que delineam, assim, um limite, além do qual se desfaz a temporalidade histórica. Esta não mais pode existir imediatamente, mas só pode ser resassumida, como pretendia Hegel, de modo mediado pelo conceito. O distanciamento em relação a estas formas puras e estruturais da mostração ou da funcionalidade pura não mais poderá deixar de ser, negativamente, um distanciamento reflectido e conceptual, ou positivamente, irónico ou retórico.

Ainda quando pretende ir além da abstracção ou do funcionalismo, a crítica ao modernismo mantém-se numa situação de reconstituição, já reflectida, de um terreno histórico, humano e simbólico anterior às formas de racionalização moderna e modernista.

\section{Modernismo e negação}

Mas não se fez ainda referência ao outro aspecto da intervenção hegeliana na história do pensamento e da sua expressão artística. Trata-se da negatividade e da oposição ou da contradição. Foi Hegel quem compreendeu a negatividade e a reflexão - com a sua função de dilaceração e afastamento da vida, - bem como a sua relação, como princípios fundadores da modernidade. A negação do existente é o que permite recomeçar de novo, como é típico dos programas modernos e modernistas, mas é também o que permite abstrair em geral, negando as diferenças e reconduzindo o existente às formas mais puras, como acontece nos abstracionismos geométricos ou na arte abstracta. A negação é expressão da liberdade em relação ao existente, ao circundante e ao solo em geral. 
O pensamento moderno funda-se na negação, ou pretende fundar-se a si mesmo dispensando algum outro solo além da sua própria capacidade reflexiva, operativa e funcional. Já o manifesto de Le Corbusier faz comparar a habitação às máquinas e, muito especialmente, às máquinas que negam o solo. Trata-se, nomeadamente, do automóvel e do avião, que imitam a casa, mas são meros habitáculos que, sobre rodas que negam o contacto fixo com o chão, ou suportados já pelo simples ar, dispensam assim a imobilidade, o próprio solo. E é referido, finalmente, o paquete, onde se habita de modo inteiramente técnico, com um afastamento integral não só do solo, mas da terra em geral e dos seus produtos, substituída inteiramente pelo metal, não só como a verdadeira máquina habitável, mas mesmo como chão metálico artificial, lançado sobre a água.

Esta auto-sustentação da razão é uma expressão da reflexão e de uma tradição de niilismo, termo que parece remontar à acusação levantada (por F. H. Jacobi) contra a filosofia de Fichte, no final do século XVIII. Segundo Jacobi, na sua Carta a Fichte de 1799, a filosofia da reflexão, que se pretende sustentar e conferir sentido a si mesma, renunciando a qualquer outro solo, representa um "niilismo". ${ }^{21}$ Se Hegel ou Fichte pretendiam que a negação e a reflexão poderiam criar um outro solo e uma "outra luz" para a emancipação humana, e uma fundamentação última na razão auto-esclarecida, subestimaram certamente o poder corrosivo da auto-suficiência da reflexão e da negação. Ou talvez, o projecto hegeliano de recuperar a positividade pela dupla negação, ou negação da negação, fosse simplesmente irrealizável, porquanto uma vez desencadeada a reflexão e a negação como operações fundamentais do pensamento, não mais é possível recuperar um solo positivo da natureza, da história ou do homem.

Em qualquer caso, a negação elevada a operação fundamental do pensar, como foi levado a cabo pelos pensadores idealistas, não resultou certamente num fim da história como uma reconciliação final, conforme pretendia Hegel, ou ainda lemos no excerto citado de Adorno, como promessa. Esperando que a negação permitisse fundar um pensamento sistemático, Hegel subestimou claramente as implicações pós-históricas, pluralistas e não-fundacionais da sua abordagem.

Por um lado, é um facto que este poder irresistível da negação e da abstracção tem um lado emancipatório. Este sistema negativo, plural e não fundacional representa uma libertação tanto da autoridade histórica dos modelos construtivos, quanto da pura funcionalidade, também esta aliás transformada em modelo histórico. Na sua análise da arquitectura de Hegel perante os desenvolvimentos actuais, Winfield observa que,

21 Jacobi, Werke III, Darmstadt, 1976, 43. 
"a arquitectura dos nossos dias encarna as formas do romantismo que Hegel identifica com o carácter formalmente independente do si-mesmo moderno. Ao reconhecer a validade universal da livre acção, a humanidade moderna não mais pode investir nenhuma configuração sensível particular com um sentido último." 22

A negatividade é uma lâmina de dois gumes. Se, por um lado, como se insistirá ainda, produziu o desenraizamento, libertou também, por outro lado, a arte da tradição, da autoridade e da própria substância ética - até porque a substância ética tendeu a transformar-se num sistema de trocas regido pela mesma negação e abstracção integrais.

\section{Sobre a reacção ao modernismo}

Por outro lado, a negatividade tornou-se permanente, e o sistema realizou o funcionalismo como troca e intercâmbio integrais de tudo e de todos. Massimo Cacciari expõe, a partir de Simmel, este dramático estádio niilista da arquitectura da cidade:

"Este drama é a emergência, ao longo do século passado [XIX], de uma arquitectura do niilismo consumado à medida que esta arquitectura chega a invadir a imagem da Metrópole: é a própria figura do pro-duzir, do deixar para trás, da ultrapassagem contínua e indefinível. A obsessão com o ultrapassar está incorporada na obra de «desenraizamento radical» levada a cabo por esta arquitectura: um desenraizamento da urbe, dos círculos sociais nela dominantes, da sua forma - um desenraizamento do lugar (como lugar da habitação) [...]. A cidade «parte» ao longo de ruas e eixos que se intersectam [...]. É como se a cidade se tivesse transformado num acaso da estrada, num contexto de rotas, num labirinto sem centro. [...] A Metrópole aparece como a grande metáfora do intelecto calculador, despido de quaisquer fins." 23

A típica ausência primitiva, pré-clássica, da relação meio e fins retorna na época do niilismo consumado, mas agora pela eliminação de quaisquer fins. Mas recorde-se que era justamente esta ausência de fins que Hegel pretendia evitar, ao colocar um termo a todos os processos de desenvolvimento, como começámos por fazer notar. Segundo Cacciari, porém, nesta ausência de termo, a Metrópole tematizada por Simmel consiste na substituição do lugar por uma funcionalidade integral. A resposta modernista, de Le Corbusier

22 Winfield, op. cit., 108.

23 Massimo Cacciari, Architecture and Nihilism: on the Philosophy of Modern Architecture, New Haven, 1993, 199-200. Tematizado por Cacciari é o ensaio de Simmel "Die Grossstädte und das Geistesleben". 
ou de Wittgenstein (ou acrescente-se, ainda hoje, de certo modo, também pós-modernista, de J. Baudrillard) é de adesão a esta funcionalidade, reconhecendo que o seu processo não é reversível por alguma espécie de reflexão da reflexão ou de negação da negação.

A negação não é um estado sustentável, mas acaba necessariamente por aplicar-se a si mesma e produzir o seu oposto, assim como a reflexão, como lógica de retorno a si, põe sempre o seu outro. A abstracção moderna vai, por conseguinte, suscitar de imediato o restabelecimento, pelo menos ideal ou idealizado, do habitar, em contraste com a homogeneidade e desenraizamento do espaço moderno. Vai igualmente recuperar o imaginário material perante o privilégio da forma e a abolição do conteúdo significativo e ornamental de muito das construções do primeiro modernismo e do estilo internacional. Vai tambem reencontrar a não-funcionalidade, em contraste com o funcionalismo integral do moderno, e restaurar o contraditório e o complexo na arquitetura, em contraste com a simplicidade aparentemente funcional da ideologia modernista, ou ainda o háptico em contraste com o predomínio moderno da perspectiva visual. ${ }^{24}$

\section{A ponte como obra de arte}

Excederia largamente os limites deste artigo abordar mais detidamente estes temas fundamentais onde o modernismo, regido pela negação, se vai negar e superar a si próprio. Limitar-me-ei, por isso, a concluir com uma referência a um aspecto da tese de Heidegger que, em reacção à mesma revolução técnica que gera o modernismo, pretende recuperar o habitar e o lugar como elementos centrais da compreensão arquitectónica. O Heidegger já tardio reflecte sobre o significado da obra de arte por excelência, a mais própria da engenharia: a ponte.

O já referido pragmatismo inerente à concepção do ser no mundo de $\mathrm{Ser}$ e Tempo de Heidegger aparece reinterpretado na sua conferência de 1951 sobre "Construir - Habitar - Pensar" como uma identidade entre o habitar e o construir. A tese de Heidegger é, simplesmente, que habitar e construir são o mesmo, mas o mesmo de tal modo que o segundo elemento deve ser reconduzido ao primeiro. Fenomenologicamente originário é o habitar, e o construir não pode ser autonomizado do habitar, por meio de uma reflexão que calcule a relação custo-benefício típica da construção técnica ordenada

24 Estas são referêncis somente programáticas a escritos de G. Bachelard (La poetique de l'espace, Paris, 1957), O. F. Bollnow (Mensch und Raum, Stuttgart, 2004), R. Venturi (Complexity and Contradiction in Architecture, trad. cast. de A. Arechavaleta, Barcelona, 2003), J. Pallasmaa (The Eyes of the Skyn, Chichester, 2005) ou Heidegger ("Bauen Wohnen - Denken" in Vorträge und Aufsätze, Günther Neske, Pfüllingen, 1954, 145-162). 
pela relação meios-fins. O habitar é, antes, uma expressão da proximidade ou familiaridade que faz do espaço um habitável não quantificável, e da distância não um dado planimétrico, mas pático, que torna o contacto possível, ou que é ela mesma já o contacto.

Por isso, segundo Heidegger, “»Eu sou«, »tu és«, quer dizer: eu moro, tu moras". E, por outro lado, "a palavra do alemão antigo para construir [bauen], »buan« significa morar. Isto quer dizer: permanecer, deter-se." 25 Ser é habitar, e habitar não se distingue de construir. Essencialmente, esta identidade significa a revalorização de um estádio da arquitectura anterior à diferença entre meios e fins, comparável ao estádio simbólico, ainda indeterminado, da consciência arquitectónica tematizado por Hegel como origem da arquitectura - mas que estranhamente se reencontra também no resultado do seu desenvolvimento, segundo Cacciari.

A construção, diz-nos Heidegger, não é um meio técnico de abrigo perante a intempérie mas, muito a montante disso, a própria criação do espaço como lugar ou sítio. A isto dá-se o nome, segundo o filósofo, de construir. $\mathrm{O}$ exemplo paradigmático da arquitectura que Heidegger apresenta na sua conferência é esclarecedor: não dá como exemplo uma casa ou um edifício de alguma outra espécie, mas a ponte. Depois de descrever as funções utilitárias da ponte, o essencial é que

“o lugar não está disponível já antes da ponte. É certo que há, antes da ponte lá estar, muitos locais ao longo da corrente que poderiam ser ocupados por algo. Um de entre eles se dá como um lugar e, com efeito, dá-se como um lugar por meio da ponte." 26

A ponte proporciona um lugar e é, por isso, uma "coisa" em sentido pleno, não essencialmente porque liga as margens, mas porque coliga o que denomina a "quaternidade" constituída por céu, terra, mortais e divinos. ${ }^{27}$ Todo o habitar e construir é atravessado por esta quaternidade, na medida em que é efectivamente lugar habitável.

No entanto, o carácter reactivo desta posição, tributário por isso ainda do niilismo e da reflexão que tão intensamente pretende recusar, encontra-se expresso na afirmação final de Heidegger, de que na Alemanha do pós-guerra, a

"crise da habitação propriamente dita não consiste na falta de casas. A verdadeira crise da habitação é também mais antiga do que a guerra mundial e as destruições [...]. A verdadeira crise da habitação reside em que os mortais procuram, ainda e sempre, a essência do habitar, que têm de começar por aprender a habitar." 28

\footnotetext{
25 M. Heidegger, op. cit, 147, 146

26 Ib., 154

27 Cf. ib, 154.

$28 \mathrm{Ib} ., 162$.
} 
Perante a assembleia de arquitectos em Darmstadt, em 1951, quando foi proferida a conferência, Heidegger procura chamar a atenção para que de nada adianta projectar e construir se perdermos o lugar do nosso habitar - diríamos talvez mesmo, se perdermos a nossa alma. Noutro contexto histórico, o carácter algo vago das teses finais do filósofo poderiam apontar para uma chamada de atenção para outras formas de concepção do espaço além do funcionalismo imediato e do valor de mercado do metro quadrado. Dado o contexto concreto, o apelo do filósofo parece-se mais com uma negação abstracta da reflexão sobre a relação meio e fim, como uma nostalgia de uma suposta originariedade pré-reflexiva, cuja superação Hegel tinha encontrado logo no limiar do desenvolvimento da arquitectura.

Mas se a ponte é o exemplo paradigmático da arquitectura, gostaria, como conclusão, de citar uma abordagem alternativa da ponte na tradição filosófica, que encontramos numa referência do já citado J. G. Fichte. Assim como na concepção do espírito em Hegel, a questão fundamental é, também para Fichte, a da reflexão, sobre a qual vimos assentar também toda a modernidade - e, afinal, já antes desta, todo o pensamento em geral. O problema filosófico não é descoberto pela reflexão como um problema objectivo, mas consiste nesta mesma possibilidade de reflectir. A questão da arte e do pensamento é sempre, na sua base, tautológica, porque é acerca do próprio haver questão. E a solução, segundo Fichte não é alguma interdição ou limitação da reflexão, conforme proposto nalgum modernismo filosófico, mas, pelo contrário, a solução é "reflectir até ao fim". ${ }^{29}$ A reflexão é o problema, mas também o próprio enunciado do problema. Este consiste, pois, justamente em que pode ser enunciado, e é, por isso - tal como vimos ser o sentido da arte, e daí o seu parentesco essencial com a filosofia - um problema da própria enunciação, e não uma questão objectiva sobre factos do mundo.

Mas, continua Fichte, ao procurarmos responder a qualquer questão e explicar algo,

"logo que dizemos 'explicar' estamos já no campo da finitude; porque todo o explicar, ou seja, o que não é um abranger de uma só vez, mas um proceder de um para o outro é algo de finito, e o limitar, ou determinar é justamente a ponte sobre a qual se passa e que o eu tem em si mesmo." ${ }^{30}$

29 Naturalmente, a interdição da reflexão é uma solução, por desaparecimento, do problema filosófico da consciência. Tal é o programa de Wittgenstein, Tractatus logicophilosophicus. Pelo contrário, segundo I. Thomas-Fogiel, a reflexão é o tema central e "structure inchangée de la philosophie de Fichte de 1793 à 1813" (I. Thomas-Fogiel, Fichte: Réflexion et argumenation, Paris, 2004, 65).

30 Fichte Gesamtausgabe I/2, Stuttgart, 1965, 412-413. 
Toda a questão pede um explicar, mas o explicar é a condição limitada e determinada da razão humana.

A condição da razão humana é, deste modo, comparável a uma ponte. Esta é uma unificação entre duas margens separadas, que só se reúnem, por definição, na nascente primeira onde se origina a corrente que separa as margens e que a ponte ultrapassa. A partir da fonte irrecuperável, as margens estão irremediavelmente separadas, a menos que a ponte as venha artificialmente reunir.

Estruturalmente, a ponte requer duas condições. Por um lado, precisa de um ponto de apoio em cada uma das margens que vai unir e, por isso, está ancorada e apoiada nas margens que une. Por outro lado, contudo, lança-se como um percurso sobre o vazio. Embora, no sentido dos seus alicerces, dependa inteiramente do fundamento dado por cada uma das duas margens, num outro sentido não depende de todo delas, mas da sua própria capacidade de auto-sustentação e coesão interna. A obra de arte é, como diz Fichte a propósito do pensamento filosófico, uma reflexão "artificial", uma ponte. O pensamento, num sentido, carece de algum fundamento exterior a ele e, noutro sentido, não carece de fundamento, mas funda-se, como uma ponte, a si mesmo. Porque não tem um fundamento em toda a sua extensão, e assenta sobre o vazio, a ponte é, assim como o eu, o seu próprio sujeito, e apoia-se em si mesma. Neste sentido, não deve ser entendida, conforme pretende Heidegger, como a geração pré-moderna de um lugar, mas cria um lugar porque se suporta a si mesma e é, por conseguinte, um empreendimento eminentemente reflexivo. Que a ponte, que apresenta para Heidegger o exemplo paradigmático da arquitectura, tem também a sua ancoragem nas margens do sujeito, não invalida o carácter de auto-sustentação que desde sempre se exigiu da obra arquitectónica. 
(Página deixada propositadamente em branco.) 